\title{
Structure and ultrastructure of oogenic stage in short mackerel Rastrelliger brachysoma (Teleostei: Scombidae)
}

\author{
SENARAT, S. ${ }^{1}$, KETTRATAD, J. ${ }^{1}$ and JIRAUNGKOORSKUL, W. ${ }^{2 *}$ \\ ${ }^{1}$ Department of Marine Science, Faculty of Science, Chulalongkorn University, Bangkok, Thailand \\ ${ }^{2}$ Department of Pathobiology, Faculty of Science, Mahidol University, Bangkok, Thailand \\ *E-mail: wannee.jir@mahidol.ac.th
}

\begin{abstract}
Introduction: Structure, ultrastructural features and degeneration of oogenesis were first investigated in female Rastrelliger brachysoma as new candidate species for aquaculture by transmission electron microscopy. Materials and Methods: Specimens were naturally collected during the breeding season from Samut Songkhram Province, Thailand. Results: The ultrastructure of female oogenesis was principally divided into five stages based on the nuclear characterization and cytoplasmic organelles; (i) oogonium; (ii) previtellogenic; (iii) lipid and cortical alveolar; (iv) early and (v) late vitellogenic stages. Initially, oogonium was present within cell nest in the epithelial compartment. Its cell was supported by prefollicular cells. The multiple nucleoli in previtellogenic stage, referring to primary growth stage were the first to appear and they were scattered around the peripheral of nuclear membrane with the increasing number of cytoplasmic organelles. Some microvilli of granulosa cell initially protruded into the vitelline envelope. A simple layer of flattened granulosa and theca cells was also observed. The lipid and cortical alveolar stage under secondary growth oocyte was accumulated with two inclusions; the lipid droplets and cortical alveoli in the ooplasm. Another characterization, the increasing of numerous microvilli was also detected in the vitelline envelope. Finally, in the vitellogenic stage, a massive uptake and processing of proteins into yolk platelets due to embedding of the numerous microvilli in the largest vitelline envelope was observed. Oocyte degeneration in $R$. brachysoma was novel found especially oogonial and previtellogenic stages. Conclusion: Five oogenic stages of this fish are found with the changing of the arrangement of nucleus, cytoplasmic organelles and follicular complex, which will be applied to further studies.
\end{abstract}

Keywords: atresia, mackerel, oogenesis, Rastrelliger brachysoma, teleost, Thailand.

\section{Introduction}

The comprehensive knowledge of the gonadal tissue in teleost fishes is mainly used to assess the reproductive biology based on sex ratio, gonadal structure, sexual maturation and reproductive cycle throughout spawning season. To understand, this provides to reflect the reproductive status and equips fisheries management with scientific advice to enable optimum exploitation (KJESBU, 2010). One of the techniques, the gonadal histology has been first required and interestingly described in detail under light microscopy before entering to other strategies in view of the above, especially numerous investigations in the family Scombridae. Such as the most commercially important fish Scomberomorus brasiliensis (CHELLAPPA, LIMA, ARAŨJO et al., 2010), and Thunnus thymus (ABASCAL and MEDINA, 2005) were seen. However, only in ultrastructural study in teleost fish, it possible to investigate the details of gametogenic processing at cellular and organelles levels (GRIER, 2000). There have been many investigations of the oogenic ultrastructure in different ways including concerning the development of oogenic stage (ABASCAL and MEDINA, 2005), development of cytoplasmic organelles and follicular cells (CRUZ-LANDIM and CRUZ-HOFLING, 2001). Although, the Scombroid species is composed of several high commercial values for fisheries, it has rarely been selected for examination. Only one Scombroid species has been described in T. thymus oogenesis (ABASCAL and MEDINA, 2005). This comprehensive result, it is necessary not only provides to understanding of the basic ultrastructural pattern and developmental processing including oogenesis, steroidogenesis and vitellogenesis in this family but also to apply for possible applications in aquaculture.

Short mackerel, Rastrelliger brachysoma as oceanodromous or migratory fish is currently considered to be of high commercial value for fisheries and a new candidate for commercial aquaculture in Thailand. As early culture technique in the late 2011 until now, several problems in its aquaculture development have been occurring. Additionally, major sources of the sexually mature $R$. brachysoma were still caught from the Upper Gulf of Thailand, which are exclusively required for the reproductive biology and the classification of oocyte development. Although, the details of ovarian structure and oogenesis of $R$. brachysoma using histology and histochemical detection have previously been primarily investigated in our laboratory using light microscope (SENARAT, KETTRATAD and JIRAUNGKOORSKUL, 2015), it has been not clearly detailed the description of the ultrastructural organizations of their oogenic stages. In this research of the present work was examined the structure and ultrastructure of the oogenic stage throughout its degeneration in short mackerel $R$. brachysoma. Novel Ultrastructural result of oogenesis in this species is lead to a better understanding of development process, corresponding to the vitellogenic and maturation in wild female germ cell. 


\section{Materials and Methods}

Ten specimens in late-developmental stage of the ovaries, sexually matured Rastrelliger brachysoma female, $17-18 \mathrm{~cm}$ (average $17.4 \mathrm{~cm}$ ) in standard length, were selected during breeding season from January to February 2014 (SENARAT, KETTRATAD and JIRAUNGKOORSKUL, 2015). The specimens were collected by bamboo strake trap from Samut Songkram Province in the Upper Gulf of Thailand $\left(13^{\circ} 16^{\prime} 18.4^{\prime \prime} \mathrm{N}, 100^{\circ} 02^{\prime} 13.4^{\prime \prime} \mathrm{E}\right)$. The fish were euthanized following to Wilson, Bunte and Carty (2009) using the rapidly cooling shock. Their gonadal tissues were prepared for ultrastructural and light microscopic studies. The present research was approved ethically by the Animal Care and Use Committee of Faculty of Science, Chulalongkorn University, Thailand (Protocol Review No. 1423003).

Light microscropic study: Small pieces of ovarian tissue were fixed in Davidson's fixative (about $24-36 \mathrm{~h}$ ) and processed using standard histological technique. $5 \mu \mathrm{m}$ sections thickness of ovarian tissue were stained with Masson's trichrome (MT) (BANCROFT and GAMBLE, 2002). The classification of the ovarian structure and oogenesis is determined according to Senarat, Kettratad and Jiraungkoorskul (2015).
Electron microscopic study: Small pieces of ovarian tissue were immediately cut and rapidly prefixed in $2.5 \%$ glutaraldehyde and postfixed in $1 \%$ osmium tetroxide. All specimens were dehydrated, embedded in Epon 812 epoxy resin and cut into $500 \mathrm{~nm}$ thickness semithin sections. The semithin sections were stained with $0.5 \%$ toluidine blue for orientation. The $90 \mathrm{~nm}$ thickness ultrathin sections were stained with uranyl acetate and lead citrate, observed and photographed using a JEM-2100 at $200 \mathrm{kV}$ transmission electron microscope. The oogenic stage was mainly examined according to the guidelines of Grier, Linton, Leatherland et al. (1980); Selman and Wallace (1986); Grier (2000) and Abascal and Medina (2005).

\section{Results and Discussion}

\subsection{Oogenic structure and ultrastucture of $R$. brachysoma}

Based on histological and semithin sections, the ovarian tissue of $R$. brachysoma was asynchronously developed (Figures 1A, 1B). Consequently, all stages of their oocyte development could be found that was divided five stages based on size, nuclear characterization and cytoplasmic organizations and schematic diagram as follows: oogonium, previtellogenic, lipid and cortical alveolar, early and late vitellogenic stages, respectively
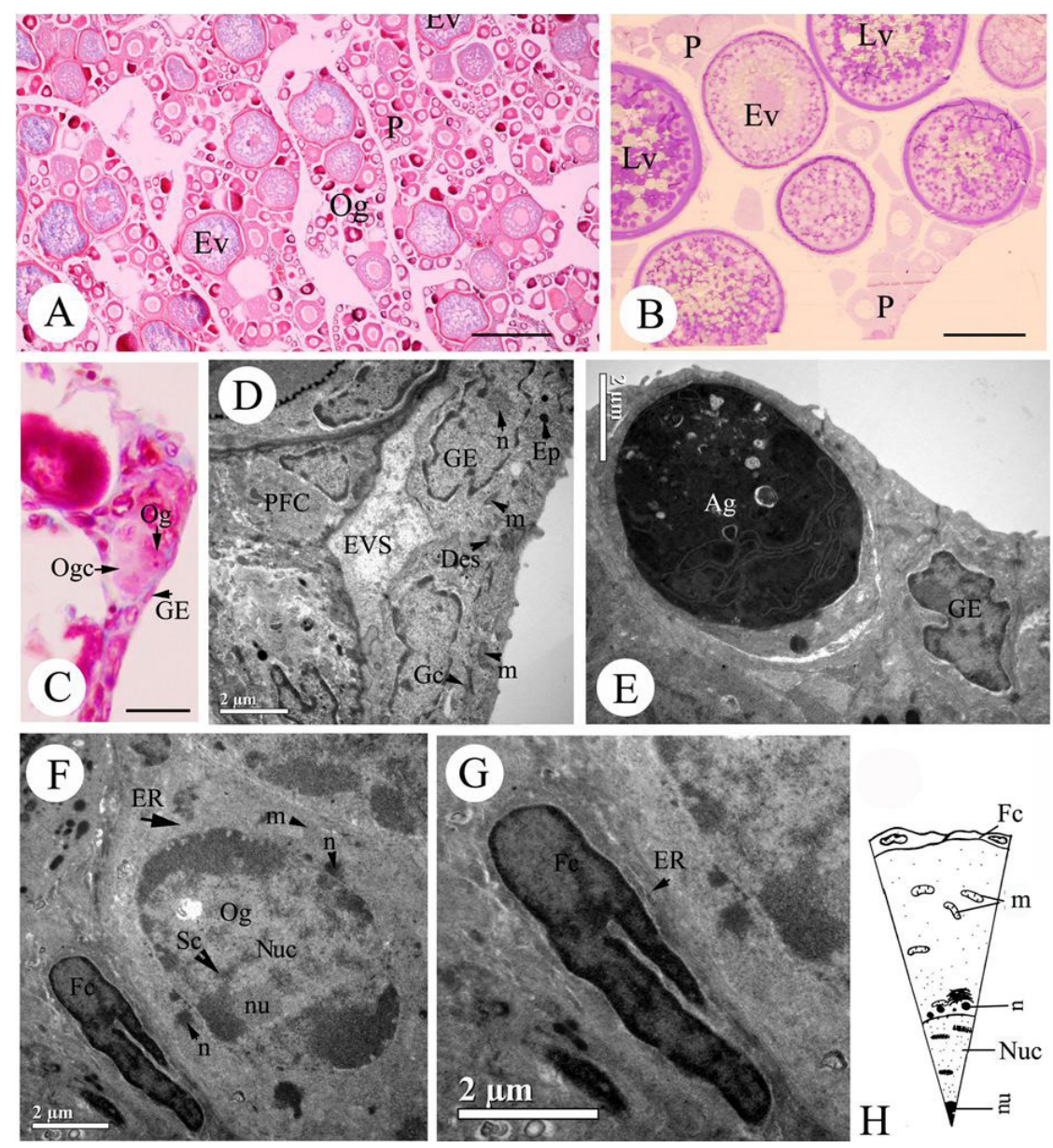

Figure 1. Light microscopic (A), transmission electron micrographs and schematic diagram of oogenesis in Rastrelliger brachysoma $(\mathrm{A}-\mathrm{H})$ including oogonia $(\mathrm{Og})$, previtellogenic $(\mathrm{P})$, lipid and cortical alveoli ( $\mathrm{Ld})$, early (Ev) and late (Lv) vitellogenic stages (A-B). Histological and thin sections showing the germinal epithelium (GE) and extracellular space (EVS) (C-E). Oogonia (Og) with surrounding the pre-follicular cell (PFC) (F-H); Ag: atretic follicle of oogonia, Des: desmosome, ER: endoplasmic reticulum, Goc: Golgi complex, m: mitochondria, n: nuage, Nuc: nucleus, nu: nucleolus, Sc: syneptonemal complex. A = $200 \mu \mathrm{m}, \mathrm{B}=50 \mu \mathrm{m}, \mathrm{C}=20 \mu \mathrm{m}$. 
According to structure and ultrastructural studies, the epithelial and stromal compartments were observed in the ovarian tissue. In the epithelial compartment was contained both germinal epithelium and somatic prefollicular cells, which were associated with oogonial cyst. Especially in the first sub-compartment, their germinal epithelium with forming into squamous epithelial cell covered the ovigerous fold (Figures 1C-1E). The characterization of its elongated cell was an irregular and flattened nucleus with a prominent a single nucleolus. Within the nucleoplasm, the condensed chromatin was also first present near nuclear membrane, whereas the information constitutions including globular mitochondria, endoplasmic reticular and electron-dense particles were poor in the cytoplasm. Sometimes, the extravascular space had relatively lucent electron-density and was also located above the basement membrane of epithelial cells (Figure 1B). The last sub-compartment, the cytoplasm processes of the somatic prefollicular cells were observed and extended around the cell nest. The presence in each cell had a triangular shape with an irregular nucleus.

The outline in a cell nest, oogonium was observed in germinal compartment and rarely appeared. Note that it was the smallest cell within the oogenic stage with a diameter at 7-8 $\mu \mathrm{m}$ in size under divided mitotically. The characterization of oogonium was unique and mainly exhibited by round nucleus (5-6 $\mu \mathrm{m}$ in diameter). Also, it was contained the syntonemal complex with a majority of finely granular chromatin. Together with nuclear components, the small single nucleolus (about $1 \mu \mathrm{m}$ in diameter) also slightly seen. Its nucleopores were numerous as electron-dense and granular material along the nuclear membrane. In the following, nuages as polymorphic organelle frequently first appeared in ultrathin section and were usually associated with mitochondria (Figures $1 F-1 \mathrm{H}$ ). Moderate amount of cytoplasm in this stage had few organelles and were poorly-developed including ribosome and ER. Mitochondria were shown round appearance with few cristae. During this stage, the cell was surrounded by pre-follicular cells, which were joined by desmosome.

In this study, the oogonium then continues growing into the primary oocyte stage, as called the early meiotic oocyte, was look like oogonium (Figures 2A). However, the characterization of this stage rarely displayed the nucleolus. Small patches of heterochromatin increased and were scatted within nucleoplasm. Golgi complex and well-development of ER in this stage were visible in ooplasm (Figures 2B-2E).

The term "the stromal compartment" seems to observe in several oocytes that the complete oogenic process could be classified into four successive stages according to the characterizations of nuclear and cytoplasmic organelles; previtellogenic, lipid and cortical alveoli, early and late vitellogenic stages. Initially, the previtellogenic stage with referring to pre-vitellogenic stage of $R$. brachysoma was more spherical than oogonium with about $20-60 \mu \mathrm{m}$ in diameter (Figures 2F-2J). Under nuclear events progress, as so-called a new feature, the nuclear membrane had numerous pores, whereas multiple micronucleoli first appeared and were scattered around the periphery of the nuclear membrane. Occasionally in electron micrographs, some nucleolus clearly showed two parts at this stage was only detectable using eletron microscropy; inner fibrillar core and outer granular periphery (Figure $2 \mathrm{H}$ ). The lucent electron-density of cytoplasmic organelles occasionally increased the number of abundant ribosomes, irregular shape (globular and tubular), whereas a few lamellar cristae of mitochondria well developed. Electron-dense and nuage bodies were also seen. At the same time in surrounding events, the layers of the follicular complex began to change (Figure 2I). The small layer of the vitelline envelope began to appear the homogeneous and moderately electron-dense material, while the granulosa cell layer exclusively started to form as elongated-flatten cells. Some microvilli of granulosa cell became longer and extended toward the oocyte surface. A distinct thin basement membrane separated the granulosa and theca layers. A continuous follicular complex, theca cell were seen. Not that, a thin squamous layer contained the small block heterochromatin and a single nucleolus.

Later, the lipid and cortical alveolar stage commenced during the beginning of secondary oocyte growth (Figures $2 \mathrm{~K}-2 \mathrm{~N}$ ). Ultrastructural study revealed the initiation of the accumulation in two inclusions (lipid droplets and cortical alveoli) during this stage. At the beginning, the lipid (120-250 $\mu \mathrm{m}$ in diameter) synthesis was first observed as homogeneous and moderate electron-dense. During our observations, its synthesis and accumulation increased in size and number, continuing throughout the vitellogenic stage, whereas cortical alveoli with fine granular materials were obviously present in the periphery of the ooplasm. Numerous organelles of weakly basophilic cytoplasm (compared to previous stage) were also exhibited such as nuage bodies, mitochondria and ER cisterna. During this stage, the vitelline envelope was clearly deposited, lightly thickened (compared to previous stage) and had longer microvilli because this characterization gradually extended from granulosa cells. Specifically, the layer of theca cell was distinctly classified into two layers; outer and inner theca cells (Figures 2M, 2N).

The vitellogenic stage could be classified into two stages; early and late vitellogenic stages. In early vitellogenic stage (Figures 3A-3G), the ooplasm contained the organelles-rich cytoplasm. Surprisingly, the initial stage was characterized by increasingly larger sized oocyte because it began to uptake and accumulates the yolk granules with moderate electron-density in the peripheral ooplasm. Therefore, it reflected the fact that the early vitellogenic stage had well-developed microvilli as abundant finger-like projections. It was exclusively embedded in the vitelline envelope while reaching maximum thickness. Moreover, according to our understanding, the events of the vitelline envelope could be classified into three layers according to localization and electron-densities. The low electron-density of outer layer (Z1) was located near the granulosa cell. The intermediated layer $(\mathrm{Z} 2)$ was thickest layer of electron-density and strongly seen, while the electron-density of the inner layer (Z3) was exhibited near oocyte surface, respectively. The granulosa cells were distinctly seen, whereas the outer thecal layer was observed as fibroblast shape. From the ultrastructure, the exogenous uptake mechanism showed that the electron-lucent materials or transport vesicles appeared in the cytoplasm of granulosa cell. At high magnification, the materials entering to pits and endocytotic vesicles (or pinocytotic vesicles) were seen to be clathrin-coated. This was indicated that it was selective transport. After that, single or multiples of coated vesicles were found in membrane of vitelline envelope. Finally, these coated vesicles coalesced to be larger vesicles (endosome) and large yolk granules at the peripheral ooplasm. Each yolk granule composed of two parts; dense central core and the peripheral granular matrix. The dense central core 

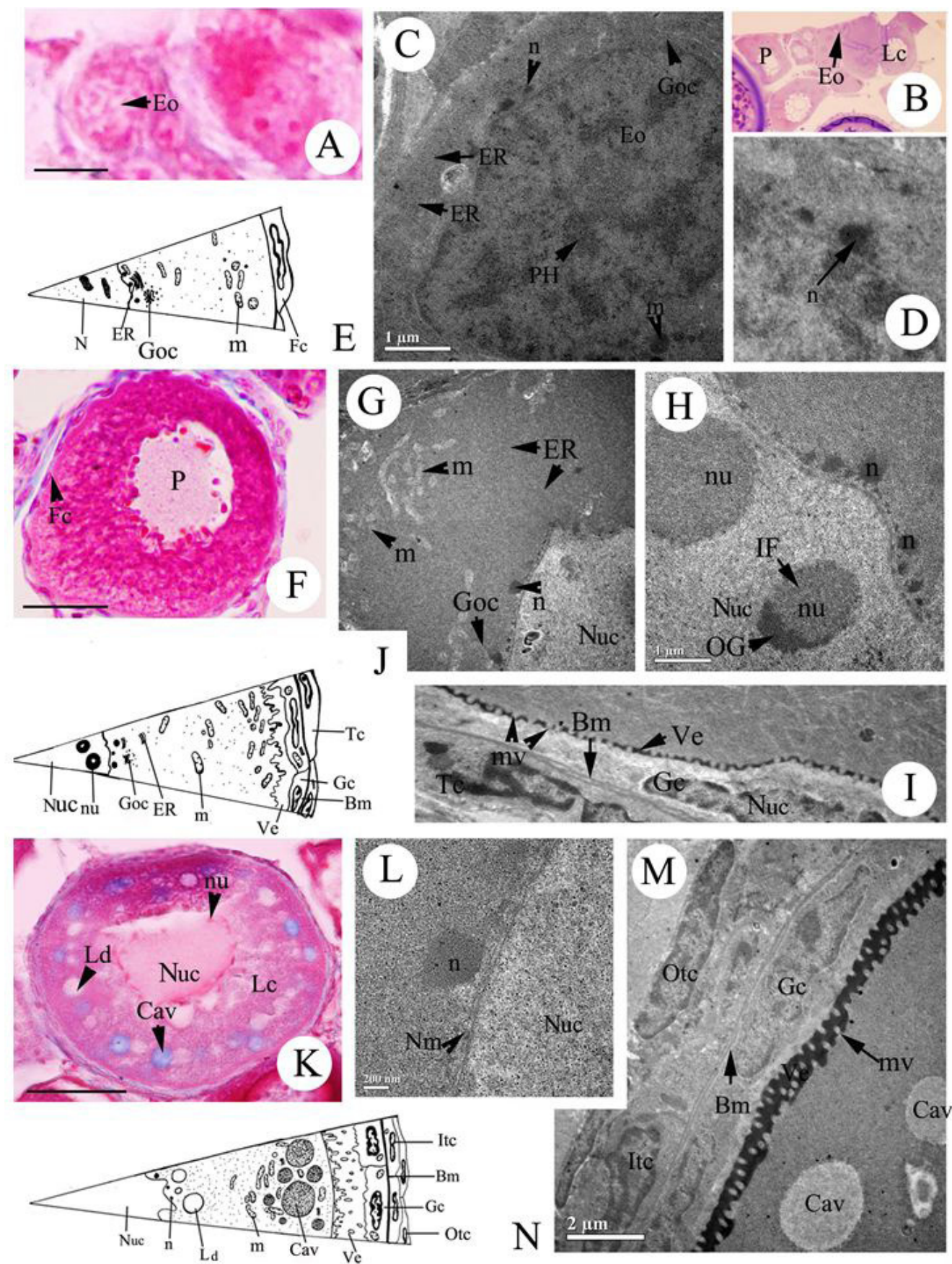

Figure 2. Light microscopic, transmission electron micrographs and schematic diagram of early meiotic oocyte (Eo), previtellogenic (P) and lipid and cortical alveoli (Lc) stages in Rastrelliger brachysoma (A-M). bm: basement membrane, Cav: cortical alveoli, ER: endoplasmic reticulums, Fc: follicular cell, Gc: granulosa cell, Goc: Golgi complex, IF: inner fibrillar core, Itc: inner theca cell, Ld: lipid droplet, m: mitochondria, mv: microvilli, n: nuage, Nuc: nucleus, Nm: nuclear membrane, nu: nucleolus, Otc: outer theca cell, Tc: theca cell, Ve: vitelline envelope. Scale bar A,F,K $=20 \mu \mathrm{m}$.

as electron dense was surrounded by the peripheral granular matrix as lucent electron dense. The cortical alveoli and the lipid droplet also increased in number and size. Moreover, they continued to accumulate their vesicles and were present in the periphery of oocyte. Cytoplasmic organelles appeared as well-developed of mitochondria, free ribosome and ER.

At the beginning of the late vitellogenic stage, no nucleus was observed in the ooplasm. Throughout this stage, yolk granules coalesced into large electron-dense yolk granules, measuring about 3-5 $\mu \mathrm{m}$ in diameter, whereas cortical alveoli also began to fuse into larger inclusions. Surrounding events, the layered vitelline envelops were still thick and followed the disorganization, respectively. Within ooplasm, the groups of mitochondria and lipid droplets were intermingled among yolk granules (Figures 3H-3M). Moreover, regression and degeneration of oocytes were normally observed during reproductive cycle in the species. 


\subsection{Structure and ultrastructure of degenerating oocytes, $R$. brachysoma}

Degeneration of oogonia with electron dense was found in this study, as called atretic follicle (Figure 4A), whereas the previtellogenic oocytes were also observed. The first visible sign of degeneration in previtellogenic stage occurred in the nucleus including the vacuolar degeneration and dense chromatin granular. The broke down of the nuclear membrane was also present. Several large vacuoles in the ooplasm appeared (Figures 4B, 4C). No microvilli together with the disintegration
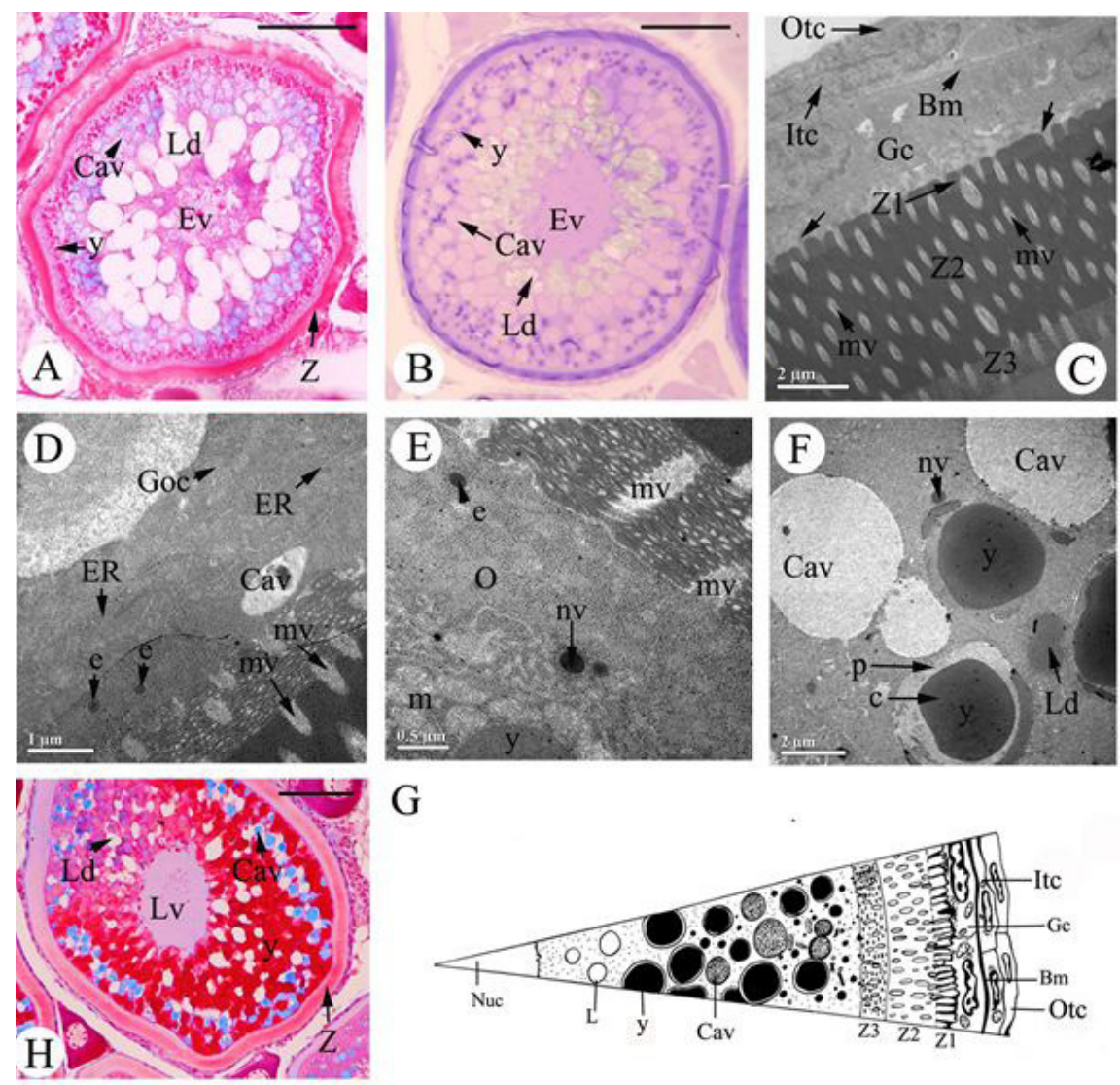

G
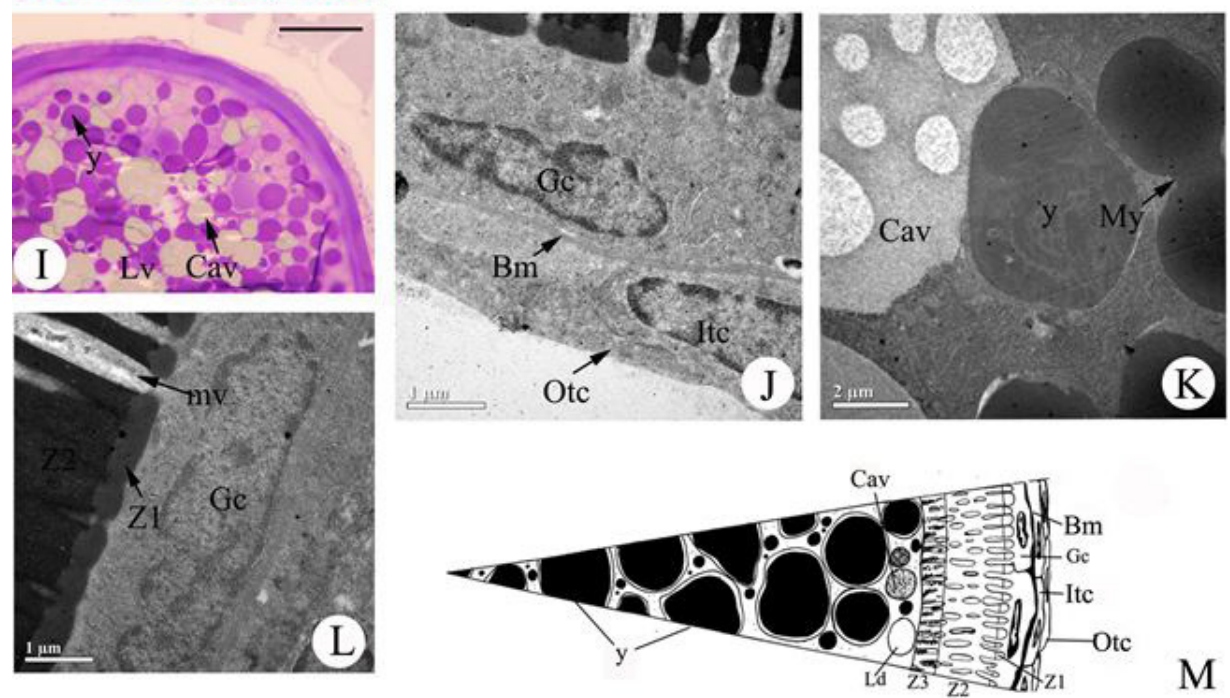

Figure 3. Light microscopic, transmission electron micrographs and schematic diagram of early and late vitellogenic stages in Rastrelliger brachysoma (A-M). Histological and semithin sections of early vitellogenic stage (Ev) (A, B). Ultrathin sections showing the detail of the increasing of vitelline envelope with consisting of 3 layers: outer $(\mathrm{Z1})$, intermediate $(\mathrm{Z} 2)$ and inner layers $(\mathrm{Z} 3)$ with several organelles in ooplasm $(\mathrm{C}-\mathrm{G})$. bl: basement membrane, c: dense central core, Cav: cortical alveoli, e: uncoated endocytotic vesicles (endosome), Gc: granulosa cell, Goc: Golgi complex, Itc: inner theca cell, Ld: lipid droplet, m: mitochondria, mv: microvilli, $\mathrm{N}$ : nucleus, ny: nascent yolk platelets, O: ooplasm, Otc: outer theca cell, p: peripheral granular matrix, RER: rough endoplasmic reticulum, SER: smooth endoplasmic reticulum, y: yolk granules, arrow: material from granulosa cell with sending to pass microvilli, arrowheads: gathering of oocyte microvilli into bundles. Scale bar A,B,H,I = $50 \mu \mathrm{m}$. 

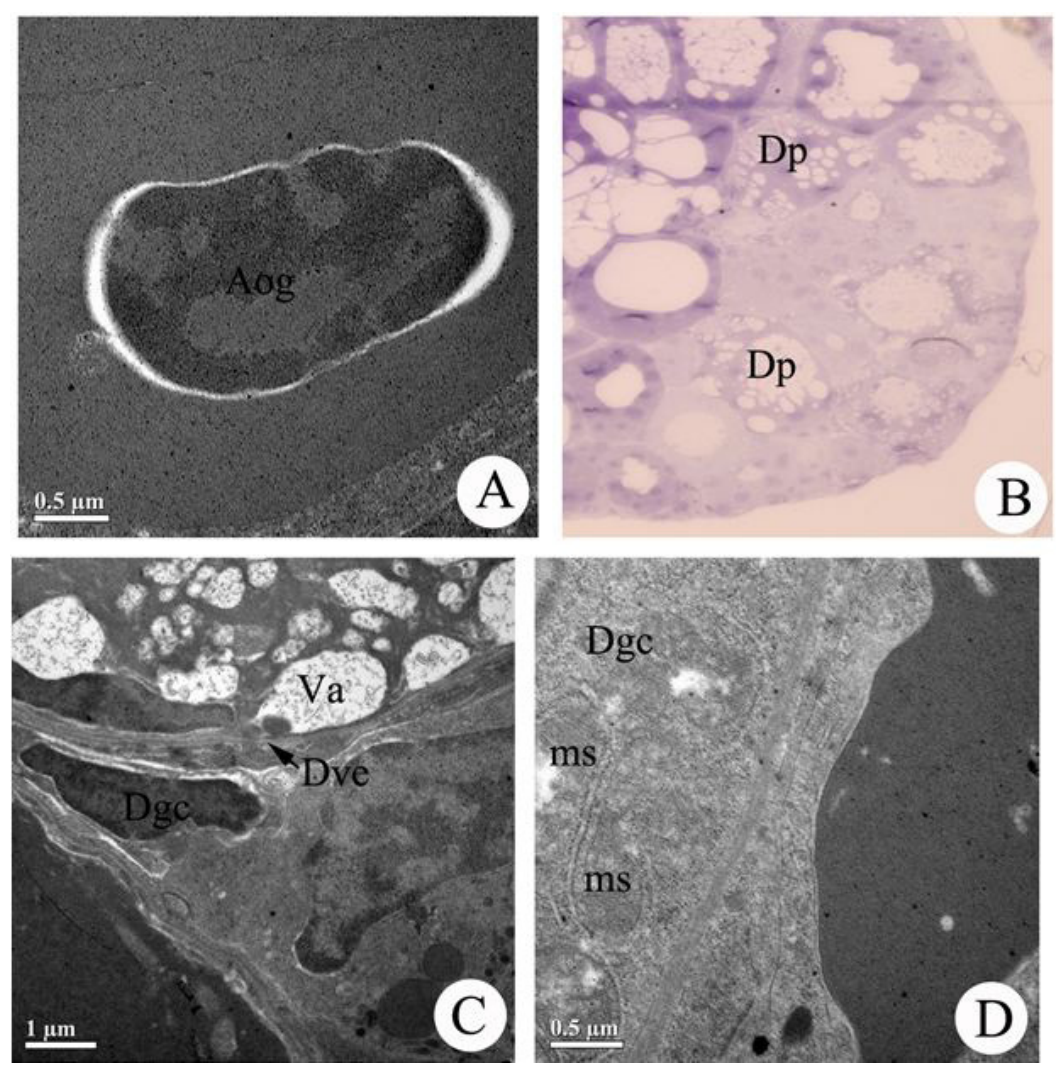

Figure 4. Transmission electron and light microscopic micrographs of atretic follicle of oogoonia (Aog) and degeneration of previtellogenic stage (Dp) in Rastrelliger brachysoma. Dgc: degernartion of granulosa cell, Dve: degeneration of vitelline envelope, ms: mitochondrial swelling, Va: vacuolar.

of vitelline envelope were visible. Finally the granulosa cell in this stage was degenerated with presenting of mitochondrial swelling (Figure 4D).

Oogenic ultrastructure in teleost fish is considered a complex process, which provides understanding of differential fine structure relating to hormonal control (SELMAN and WALLACE, 1986; SELMAN, WALLACE and BARR, 1986). In this study we reveal the first reported ultrastructural analysis mainly as used to assess the oogenic step in $R$. brachysoma and classified the differentiating oocytes into five stages including oogonium, early meiotic stage, primary (referring to previtellogenic stage) and secondary (referring to lipid-cortical alveolar and vitellogenic stages) growth stages throughout the degeneration of oocytes. Although to study the oogenic ultrastructure of $R$. brachysoma has been similarly described in some fishes (ABDALLA and CRUZ-LANDIM, 2003; ABDEL-AZIZ, AL-OTAIBI, OSMAN et al., 2012), the use of TEM provided us to better the understanding the components in both cellular and organelles during oogenic process of this species. The prominent characterization of oogonium as well as earliest stage had nucleolar materials with several nuages, in which the common feature did not differ from previously described in several authors (ABDALLA and CRUZ-LANDIM, 2004). The appearance of the nuages in this stage, $R$. brachysoma referring to the electron-dense masses, from the fact that were scatted and observed in association with mitochondria near nuclear membrane throughout the lipid and cortical stage, as similar to that of Piaractus mesopotamicus (ABDALLA and CRUZ-LANDIM, 2004). Previous suggestion is supported that nuage may involve the oogenic development for fishes because the synthetic activity of the ribonucleoprotein with ribosomic content is found in this structure (ALBERTS, JOHNSON, LEWIS et al., 2007). As in different teleosts, the unique complexity of the primary growth stage was pronounced initially by increasing basophilia with reflecting to the active synthesis of RNAs and the accumulation of ribosome with mitochondria, while the nucleus contained the multiple nucleoli in a perinuclear position of the nuclear membrane (SELMAN and WALLACE, 1986; SELMAN, WALLACE and BARR, 1986). Prominent characterization of this stage in agreement with previous findings in Dicentrachus labrax (MAYER, SHACKLEY and RYLAND, 1988) and R. brachysoma (present study).

Other important findings during the following secondary growth stage, the small lipid droplets first appeared, gradually became more abundant and increased in size at the vitellogenic stage, which is dominantly characterized as commonly observed in some marine fishes (DE VLAMING, 1983). Under light microscopy, the accumulation of lipid droplet showed the empty apace or vacuolar because of the extraction of its content during the histological method, however, Oil red O staining was positively reacted (Unpublished data). Recent data with the multifunction of this structure is well-known and associated with the nutrients for the development of the future embryo (ABASCAL and MEDINA, 2005). As following to the cortical alveoli were continuously developed and 
gradually increased in the ooplasm, suggesting that this was highly active in glycoprotein synthesis activity (based on MT stating (Unpublished data). This feature is similarly reported in many other fish species (DE VLAMING, 1983; SELMAN, WALLACE and BARR, 1986, 1988). The development of the cortical alveoli may be involved in processing the cortical reaction at fertilization and polyspermy (DE VLAMING, 1983; SELMAN and WALLACE, 1986; SELMAN, WALLACE and BARR, 1986, 1988).

When oocytes turn into vitellogenesis, the formation of the small yolk granules in ooplasm of the early vitellogenic stage and their large granules in later stage (late vitellogenic stage) were seen. A parallel fluctuation to morphological events during oogenic process, the vitelline envelope was also interestingly formed. Particularly clear evidence at the previtellogenic stage, the vitelline envelope was first seen and distinctly embedded by several microvilli that extended from granulosa cells. Then, the vitelline envelop became the thickest layer together with several microvilli during vitelligenic stages. Hence, it is apparent that these changes are closely associated to be highly specific with an increasing level of vitellogenin as well as yolk granules, which is highly observed in vitellogenic stage. This feature is similarly reported in several marine fish, as for instance, in Pagrus major (MATSUYAMA, NAGAHAMA and MATSURA, 1991) and Chionodraco hamatus (BALDACCI, TADDEI, MAZZINI et al., $2001)$. It is well known that this process is normally regulated by hypophyseal hormones as well as hypothalamo-pituiatry gonadal axis, like other fishes (SELMAN, WALLACE and BARR, 1986, 1988). The pathway of yolk uptake into the ooplasm, this is well known with reporting in several species for example Cyprinodon variegatus (SEIMAN and WALLACE, 1982) and Fundulus heteroclitus (SELMAN and WALLACE, 1983). All cases and our observation showed that circulating macromolecules are passed to endothelial cells of the thecal capillaries and then transported to granulosa cell (referred as follicle cells) and through the pore cannels of vitelline envelope. When the uptake of yolk granules from the granulosa cell to ooplasm, it was also selective by endocytosis, then translocate to the nascent yolk platelets and yolk granules, as confirmed by Koç and Akbulut (2012) too. In further work, the direct experiment evidence supporting the purification and level of vitellogenin from ovarian tissue using SDS-PAGE and western blot analyses is remains unknown, which are still to be explored.

Interestingly, we also showed the organization of vitelline envelope in the vitellogenic stage, three layers; the outer, intermediate and inner layers were found, as like to Serrasalmus spilopleura (QUAGIO-GRASSIOTTO and GUIMARÃES, 2003). However, in some species, it differed from other fish species such as two layers in $P$. major (MATSUYAMA, NAGAHAMA and MATSURA, 1991). Considering to this characterization would suggest the layer of vitelline envelope; it may be associated with types of reproductive strategies. Quagio-Grassiotto and Guimarães (2003) provided evidence that the vitelline envelope of oviparous species was thicker than viviparous. This result had led to the suggestion that $R$. brachysoma was considered as oviparous.

An important conclusion from this study was that, a preliminary nature in the oogenic stages of $R$. brachysoma female including oogonium, previtellogenic, lipid and cortical alveolar, early and late vitellogenic stages throughout the degenerating oocytes. It accurately provided a better understanding during oogenic process will improve and increase the $R$. brachysoma productivity during aquacultural development. Further studies, the identification of the neurotransmitters, the neuropeptides and sex hormonal levels relating to ovarian development in this species will be observed, as described later.

Acknowledgements: This work was supported by The $100^{\text {th }}$ Anniversary Chulalongkorn University Fund for Doctoral Scholarship. The authors wish to thank Dr. Watiporn Yenchum for suggestions and comments. Also, the members of the Fish Research Unit, Department of Pathobiology, Faculty of Science, Mahidol University and Department of Marine Science, Faculty of Science, Chulalongkorn University for their support throughout this study. We also specially thank Dr. David V. Furman and Mr. Rahul Mehrotra for reading the grammatical structure in this manuscript.

\section{References}

ABASCAL, FJ. and MEDINA, A. Ultrastructure of oogenesis in the bluefin tuna, Thunnus thynnus. Journal of Morphology, 2005, vol. 264, n. 2, p. 149-160. PMid:15759286.

ABDALLA, FC. and CRUZ-LANDIM, C. Some histological and ultrastructural aspects of oogenesis in Piaractus mesopotamicus Holmberg, 1887 (Teleostei). Brazilian Journal of Morphological Sciences, 2003, vol. 20, n. 1, p. 3-10.

ABDALLA, FC. and CRUZ-LANDIM, C. Occurrence and ultrastructural characterization of "nuage" during oogenesis and early spermatogenesis of Piaractus mesopotamicus Holmberg, 1887 (Teleostei). Brazilian Journal of Morphological Sciences, 2004, vol. 64, n. 3B, p. 555-561. PMid:15619993.

ABDEL-AZIZ, SH., AL-OTAIBI, M., OSMAN, AM., ALI, TE. and BAWAZEER, F. Ultrastructural evidence of oogenesis of the rusty parrotfish, Scarus ferrugineus (Teleostei: Scaridae). Copeia, 2012, vol. 2 , n. 2 , p. 229-236.

ALBERTS, B., JOHNSON, A., LEWIS, J., RAFF, M., ROBERTS, K. and WALTER, P. Molecular biology of the cell. 5 th ed. New York: Garland Science, 2007. p. 1392.

BALDACCI, A., TADDEI, AR., MAZZINI, M., FAUSTO, AM., BUONOCORE, F. and SCAPIGLITI, G. Ultrastructure and proteins of the egg chorion of the Antarctic fish Chionodraco hamatus (Teleostei, Notothenioidei). Polar Biology, 2001, vol. 24, n. 6, p. 417-421.

BANCROFT, JD. and GAMBLE, M. Theory and practice of histological techniques. London: Churchill Livingstone, 2002.

CHELLAPPA, S., LIMA, JTAX., ARAŨJO, A. and CHELLAPPA, NT. Ovarian development and spawning of Serra Spanish mackerel in coastal waters of Northeastern. Brazilian Journal of Biology $=$ Revista Brasileira de Biologia, 2010, vol. 70, n. 2, p. 451-456. PMid:20379657.

CRUZ-LANDIM, C. and CRUZ-HOFLING, MA. Ultrastructure of the ovarian follicular epithelium of the amazonian fish Pseudotylosurus microps (Gunther) (Teleostei: Belonidae). I. The follicular cells cycle of development. Revista Brasileira de Zoologia, 2001, vol. 18, n. 1, p. 99-109.

DE VLAMING, V. Oocyte developmental patterns and hormonal involvements among teleosts. In RANKIN, JC., DUGGAN, RT. and PITCHER TJ. (Eds.). Control processes in fish physiology. London: Springer, 1983. p. 176-199.

GRIER, H. Ovarian germinal epithelium and folliculogenesis in the common snook, Centropomus undecimalis (Teleostei: Centropomidae). Journal of Morphology, 2000, vol. 243, n. 3, p. 265-281. PMid:10681472.

GRIER, HJ., LINTON, JR., LEATHERLAND, JF. and DE VLAMING, VL. Structural evidence for two different testicular types in teleost fishes. The American Journal of Anatomy, 1980, vol. 159, n. 3, p. 331-345. PMid:7211713. 
KJESBU, OS. The utility of gonad histology in studies of fish reproduction and the subsequent management of fisheries and ecosystems. In WYANSKI, DM. and BROWN-PETERSON NJ. (Eds.). Proceedings of the 4th Workshop on Gonadal Histology of Fishes, 2010. El Pueto de Santa Maria, Spain. 2010.

KOÇ, ND. and AKBULUT, C. Electron and light microscopic investigations of follicular epithelium in vitellogenic oocyte of zebrafish (Danio rerio). Pakistan Journal of Zoology, 2012, vol. 44, n. 6, p. 1581-1586.

MATSUYAMA, M., NAGAHAMA, Y. and MATSURA, S. Observations on ovarian follicle ultrastructure in the marine teleost, Pagrus major during vitellogenesis and oocyte maturation. Aquaculture, 1991, vol. 92 , p. 67-82.

MAYER, I., SHACKLEY, SE. and RYLAND, JS. Aspects of the reproductive biology of the bass, Dicentrarchus labrax L. I.: an histological and histochemical study of oocyte development. Journal of Fish Biology, 1988, vol. 33, p. 609-622.

QUAGIO-GRASSIOTTO, I. and GUIMARÃES, ACD. Follicular epithelium, theca and egg envelope formation in Serrasalmusspilopleura (Telestei, Characifroms, Characidae). Acta Zoologica, 2003, vol. 84, n. 2, p. 121-129.

SELMAN, K. and WALLACE, RA. Oocyte growth in the sheepshead minnow: uptake of exogenous proteins by vitellogenic oocytes. Tissue of Cell, 1982, vol. 14, n. 3, p. 555-571. PMid:7147228.
SELMAN, K. and WALLACE, RA. Oogenesis in Fundulus heteroclitus. III. Vitellogenesis. The Journal of Experimental Zoology, 1983, vol. 226, n. 3, p. 441-457. PMid:6886667.

SELMAN, K. and WALLACE, RA. Gametogenesis in Fundulus heteroclitus. American Zoologist, 1986, vol. 26, p. 173-192.

SELMAN, K., WALLACE, RA. and BARR, V. Oogenesis in Fundulus heteroclitus. IV. Yolk vesicle formation. The Journal of Experimental Zoology, 1986, vol. 239, n. 1, p. 277-288.

SELMAN, K., WALLACE, RA. and BARR, V. Oogenesis in Fundulus heteroclitus. V. The relationship of yolk vesicles and cortical alveoli. The Journal of Experimental Zoology, 1988, vol. 246, n. 1, p. 42-56.

SENARAT, S., KETTRATAD, J. and JIRAUNGKOORSKUL, W. Morpho-histology of the reproductive duct in short mackerel Rastrelliger brachysoma (Bleeker, 1865). Advance in Environmental Biology, 2015, vol. 8, n. 8, p. 210-215.

WILSON, JM., BUNTE, RM. and CARTY, AJ. Evaluation of rapid cooling and tricaine methanesulfonate (MS222) as methods of euthanasia in zebrafish (Danio rerio). Journal of the American Association for Laboratory Animal Science, 2009, vol. 48, n. 6, p. 785-789. PMid:19930828. 